\title{
Contrast Medium Controlled Injection in the Navicular Bursa and the Following Bursography in 23 Cases
}

\author{
Christian Staufenbiel* and Jens Körner \\ Hanseklinik für Pferde, Karl-Benz-Str. 5-7, 27419 Sittensen, Germany
}

*Corresponding author: Christian Staufenbiel, Nindorfer, Hanseklinik für Pferde, Karl-Benz-Str. 5-7, 27419 Sittensen, Germany

\section{ARTICLE INFO}

Received: 幽 September 23, 2021

Published: 㓞 December 16, 2021

Citation: Christian Staufenbiel, Jens Körner. Contrast Medium Controlled Injection in the Navicular Bursa and the Following Bursography in 23 Cases. Biomed J Sci \& Tech Res 40(4)-2021. BJSTR. MS.ID.006476.

ABSTRACT

Equine palmar foot syndrome or navicular disease is a common cause of chronic front limb lameness. The state-of-the-art magnetic resonance imaging is not available for all patients and ultrasonography is sometimes impossible. Intrabursal medication is an important part of treating the disease. Contrast-enhanced (CE) radiography seems to be another interesting imaging modality. There is no information about the CE dorsoproximal-palmarodistal oblique (DPr-PaDiO) radiographs in living horses. This case study shows the first results of this imaging technique with explanations of the findings. Twenty out of 23 injections were successful. The navicular bursa (NB) and the distal interphalangeal joint were filled with contrast medium (CM) in $1 / 23$. There was CM palmar to the deep digital flexor tendon (DDFT) in addition to the filled NB in $5 / 20(25 \%)$ cases. The DPr-PaDiO CE showed alliterations in $7 / 9$ (77.78 \%) with a clinical history of lameness. There were two DDFT lesions, one full flexor cortex lesion, three suspected ruptures of the NB and five NB adhesions. The DPr-PaDiO CE X-ray is an inexpensive and highly available additional imaging tool in horses with suspected equine palmar foot syndrome.
\end{abstract}

Abbreviations: Papr-Padio: Palmaroproximal-Palmarodistal Oblique; Dpr-Padio: Dorsoproximal-Palmarodistal Oblique; DDFT: Deep Digital Flexor Tendon; MRI: Magnetic Resonance Imaging; CE: Contrast-Enhanced; NB: Navicular Bursa; DIP: Distal Interphalangeal (Joint); CSL: Collateral Sesamoidean Ligament; DIL: Distal Impar Ligament

\section{Introduction}

Equine palmar foot syndrome is a common cause of front limb lameness in the horse [1]. The podotrochlear apparatus is a special anatomic feature in the horse due to the deep digital flexor tendon needing a pulley before the insertion on the distal phalanx. The navicular bone (navicular bursa: NB), distal impar ligament (DIL), collateral sesamoidean ligaments (CSL) and the deep digital flexor tendon (DDFT) are part of the podotrochleat apparatus [2]. Alliterations of one of these structures alone or combined lead to pain [2]. Magnetic resonance imaging (MRI) is a favorable method to diagnose the different lesions [3-5]. Ultrasound is also an option to diagnose changes in the DIL and DDFT [6,7]. Due to lesions in the soft tissue, X-ray is sufficient to diagnose equine palmar foot syndrome [8]. Contrast radiography with palmaroproximal-palmarodistal oblique views seem to be helpful in diagnosing changes in the DDFT and the flexor surface cartilage $[9,10]$. Intrabursal medication is one of the widest use practices in navicular disease $[11,12]$.

There are many ways to inject the bursa. The distal palmar approach to the "navicular position," defined as a point on the lateral hoof wall, $1 \mathrm{~cm}$ distal to the coronary band, and halfway between the most dorsal and most palmar aspect of the coronary band [12], seems to be very successful. In cadaver limbs, 23/25 (92\%) were injected successful with 1.1 redirection per injection. However, 
there was also contrast medium (CM) in the distal interphalangeal joint (DIP) in 1/25 (4\%) and palmar to the DDFT in $1 / 25$ (4\%) legs. There is also the possibility to show alliterations in navicular apparatus in cadaver limbs with bursography, especially with the dorsoproximal-palmarodistal oblique view [13]. There is a reported success of $14 / 17$ for NB injections (82.35 \%) in living horses [14]. There is no information currently about dorsoproximalpalmarodistal oblique radiographic projections with $\mathrm{CM}$ in the NB in living horses. Thus, this case study will show the first results of this technique in living horses.

\section{Materials and Methods}

Thirteen horses were chosen for a reason not connected to the study for injection of the NB. Patients were presented in the hospital from 2015 to 2020 and were all warmbloods. Nine horses were injected in both front feet. Only one foot was injected in each of four horses. The NB was injected twice in one horse. There was complete lameness examination data available in seven horses, including a positive distal digital nerve block. The data were collected retrospectively. All horses underwent a distal digital nerve block and a sedation with detomidine and butorphanol. The skin between the heel bulbs was shaved or clipped and washed for 5 min with antibacterial soap and swabbed several times with alcohol. The foot was placed on a standard DP $65^{\circ}$ wooden block and held by staff, the same way as for the DPr-PaDiO radiographic projections. An amount of $3 \mathrm{ml}$ Iomeprol $300 \mathrm{mg}$ ID/ml (Imeron 300M@ Bracco Imaging $\mathrm{GmbH}$, Konstanz, Germany) and $5 \mathrm{mg}$ triamcinolonactenonide (TriamHexal@), Hexal AG, Holzkirchen, Germany) were injected directly into the NB using a spinal needle (BDC) Spinal Needle, $0.9 * 90 \mathrm{~mm}$, Becton Dickinson GmbH, Karlsruhe, Germany) and a standard $5 \mathrm{ml}$ syringe under sterile conditions.

The landmark for needle insertion was a point just proximal to the central sulcus of the frog, with the needle directed toward the apex of the frog and parallel to the ground surface of the hoof [10]. The correct placement of the needle was controlled with a latero-medial view. If the needle was not in place, it was redirected and also checked with an latero-medial view until it was correctly placed. The CM was then injected and another latero-medial view was taken to see whether the bursa was filled with $\mathrm{CM}$. Holding the leg still in position, the DPr-PaDiO radiographic projection and a palmaroproximal-palmarodistal oblique (PaPr-PaDiO) radiograph on a standard block were made. All radiographs were acquired with a mobile X-ray tube (TR 90/30, Gierth ${ }^{\circledR}$, Riesa, Germany) and a direct X-ray detector system (Mark 3 Sound-Eklin ${ }^{\circledR}$ Carlsbad, CA, USA or CXDI-801C, Canon ${ }^{\circledR}$, Tokyo, Japan).

Findings in the DPr-PaDiO CE were a change in dimension of the proximal or distal border, which represents an adhesion formation. The rough shape of the NB might come from a chronic bursitis with hyperproliferation of the synovium. Additionally, there should be no CM abaxial to the border marked by the end of the navicular bone, which would be evidence of a rupture of the NB. A dorsal tendon tear would lead to a long, straight and radiopaque line. Therefore, if there is an irregularity in the surface of the DDFT communicating with the NB, CM would be able to fill the defect in the tendon. A defect in the flexor cortex (cartilage) would manifest as a round, radiopaque area. These lesions are typically roundshaped. An adhesion would be represented by a radiolucent area. As described above, there is a small amount of CM between the navicular bone and the DDFT. If there is an adhesion between those structures mentioned, the dye column will be interrupted. The radiological density of the scar tissue is like soft tissue, therefore, there will be radiolucency.

\section{Results/Observations}

Twenty-three legs were injected. The NB was successfully injected only in 20/23 (86.96 \%). In the other three legs, the CM was injected completely palmar to the DDFT (Figure 1b). The NB and the DIP were filled with CM in one horse (4.35 \%) (Figure 1a). The DPr-PaDiO CE showed alliterations in 7/9 (77.78 \%) legs with a clinical history of lameness. There was CM palmar to the DDFT (Figure 1a) and the NB was filled with CM in 5/20 (25.00\%) legs. The findings are summarized in Table 1 . There were two DDFT lesions, one full flexor cortex lesion, three suspected ruptures of the NB and five NB adhesions.

Table 1: Table 1 shows the information about the horses, results of the injection and radiographic evaluation. $+=$ positive and $-=$ negative, n.a. $=$ not available

\begin{tabular}{|c|c|c|c|c|c|c|c|c|}
\hline No. & History & Side & $\begin{array}{c}\text { Lame- } \\
\text { ness }\end{array}$ & $\begin{array}{l}\text { Successful } \\
\text { injection }\end{array}$ & $\begin{array}{l}\text { CM palmar } \\
\text { DDFT }\end{array}$ & DPr-PaDiO CE & PaPr-PaDiO CE & Remarks \\
\hline 1 & + & $\mathrm{r}$ & $2 / 5$ & + & + & not evaluable & $\begin{array}{c}\text { dorsal fibrillation of the DDFT, } \\
\text { thinning of the flexor surface } \\
\text { cartilage }\end{array}$ & filling of the DIP joint \\
\hline 2 & + & $\mathrm{r}$ & $2 / 5$ & + & - & suspected tendon lesion & suspected tendon lesion & $\begin{array}{l}\text { dorsal DDFT lesions } \\
\text { confirmed with MRI }\end{array}$ \\
\hline 3 & + & $\mathrm{r}$ & $3 / 5$ & + & - & $\begin{array}{l}\text { flexor surface full cortex } \\
\text { lesion, NB adhesion }\end{array}$ & $\begin{array}{l}\text { flexor surface full cortex } \\
\text { lesion, suspected DDFT } \\
\text { fibrillation }\end{array}$ & acute onset lameness, \\
\hline $4 a$ & - & 1 & n.a. & + & + & medication visible & not remarkable & $\begin{array}{c}10 \mathrm{mg} \\
\text { triamcinolonacetonide }\end{array}$ \\
\hline
\end{tabular}




\begin{tabular}{|c|c|c|c|c|c|c|c|c|}
\hline $4 \mathrm{~b}$ & - & $\mathrm{r}$ & n.a. & + & - & medication visible & not remarkable & $\begin{array}{l}10 \mathrm{mg} \\
\text { triamcinolonacetonide }\end{array}$ \\
\hline $5 a$ & - & 1 & n.a. & + & - & not remarkable & not remarkable & \\
\hline $5 b$ & - & $\mathrm{r}$ & n.a. & + & - & not remarkable & not remarkable & \\
\hline $6 a$ & - & l & n.a. & + & + & medication visible & not remarkable & \\
\hline $6 b$ & - & $\mathrm{r}$ & n.a. & + & - & $\begin{array}{l}\text { medication visible, } \\
\text { distal adhesion }\end{array}$ & not remarkable & $\begin{array}{l}10 \mathrm{mg} \\
\text { triamcinolonacetonide }\end{array}$ \\
\hline $7 a$ & - & l & n.a. & - & + & not evaluable & not evaluable & $\begin{array}{l}\text { complete injection } \\
\text { palmar DDFT }\end{array}$ \\
\hline $7 \mathrm{~b}$ & - & $\mathrm{r}$ & n.a. & - & + & not evaluable & not evaluable & $\begin{array}{l}\text { complete injection } \\
\text { palmar DDFT }\end{array}$ \\
\hline $8 a$ & - & l & n.a. & + & - & not remarkable & not remarkable & massive $\mathrm{OA}$ pastern joint \\
\hline $8 b$ & - & $\mathrm{r}$ & n.a. & + & - & not remarkable & not remarkable & massive $\mathrm{OA}$ pastern joint \\
\hline $9 a$ & - & 1 & n.a. & + & + & not remarkable & not remarkable & \\
\hline $9 \mathrm{~b}$ & - & $\mathrm{r}$ & n.a. & - & + & not evaluable & not evaluable & $\begin{array}{l}\text { complete injection } \\
\text { palmar DDFT }\end{array}$ \\
\hline $10 \mathrm{a}$ & + & l & $2 / 5$ & + & - & $\begin{array}{c}\text { rupture of the NB, } \\
\text { rough shape of NB, NB } \\
\text { adhesions }\end{array}$ & $\begin{array}{l}\text { thinning of the flexor surface } \\
\text { cartilage }\end{array}$ & \\
\hline $10 \mathrm{~b}$ & + & $\mathrm{r}$ & $2 / 5$ & + & - & unregular shape of NB & $\begin{array}{l}\text { thinning of the flexor surface } \\
\text { cartilage }\end{array}$ & \\
\hline $11 \mathrm{a}$ & + & l & $3 / 5$ & + & - & $\begin{array}{c}\text { suspected advanced } \\
\text { tendon lesion, NB } \\
\text { adhesions }\end{array}$ & $\begin{array}{l}\text { suspected advanced tendon } \\
\text { lesion, dorsal fibrillation }\end{array}$ & $\begin{array}{c}\text { 28.05.2019 same horse } \\
\text { as } 11 \mathrm{~b}\end{array}$ \\
\hline $11 b$ & + & l & $3 / 5$ & + & + & $\begin{array}{l}\text { suspected massive } \\
\text { tendon lesion, NB } \\
\text { adhesions }\end{array}$ & $\begin{array}{l}\text { suspected advanced tendon } \\
\text { lesion, dorsal fibrillation }\end{array}$ & $\begin{array}{l}21.08 .2019 \text { massive } \\
\text { progression compared to } \\
\text { a), DDFT lesion visible in } \\
\text { ultrasound }\end{array}$ \\
\hline $12 \mathrm{a}$ & + & 1 & $1 / 5$ & + & - & medication visible & not remarkable & \\
\hline $12 b$ & + & $\mathrm{r}$ & $1-2 / 5$ & + & - & rupture of the NB & irregular filling of NB & $\begin{array}{c}\text { acute lameness after } \\
\text { injection }\end{array}$ \\
\hline $13 a$ & - & l & n.a. & + & - & $\begin{array}{l}\text { rupture of the NB, } \\
\text { proximal NB adhesion }\end{array}$ & irregular filling of NB & \\
\hline $13 \mathrm{~b}$ & - & $\mathrm{r}$ & n.a. & + & - & not remarkable & not remarkable & \\
\hline
\end{tabular}



\section{Figure 1:}

a. There is contrast medium $(\mathrm{CM})$ in the navicular bursa and the distal interphalangeal joint, and some CM palmar to the deep digital flexor tendon (DDFT)

b. The injection of the navicular bursa has failed. The CM is completely palmar to the DDFT. 


\section{Special Cases}

Horse 3 was presented at the hospital because of an acute onset of lameness in the right front two weeks previously. The referring vet made a DPr-PaDiO X-ray. There was a central radiolucent area in the navicular bone that was suspected of being an osseus cystlike lesion (OCLL). The lameness was alleviated by a distal digital nerve block in the clinic. The DPr-PaDiO was repeated and an additional PaPr-PaDiO X-Ray was done. The OCLL was seen again in both views. An intrabursal administration of corticosteroids was recommended and a systemic treatment with bisphosphonates as therapy. The DPr-PaDiO CE radiographs showed a radiopaque area exactly in the middle of the suspected OCLL. The proximal and distal border of the NB also seemed to be very irregular (Figure 2a). The finding could be revealed in the PaPr-PaDiO CE (Figure 2b). The diagnosis was a full thickness flexor cortex lesion including the subchondral bone and bursitis of the NB. The prognosis given was poor. The horse was three month better with the therapy. It was euthanized after three months because of the poor prognosis and the recurrent lameness.

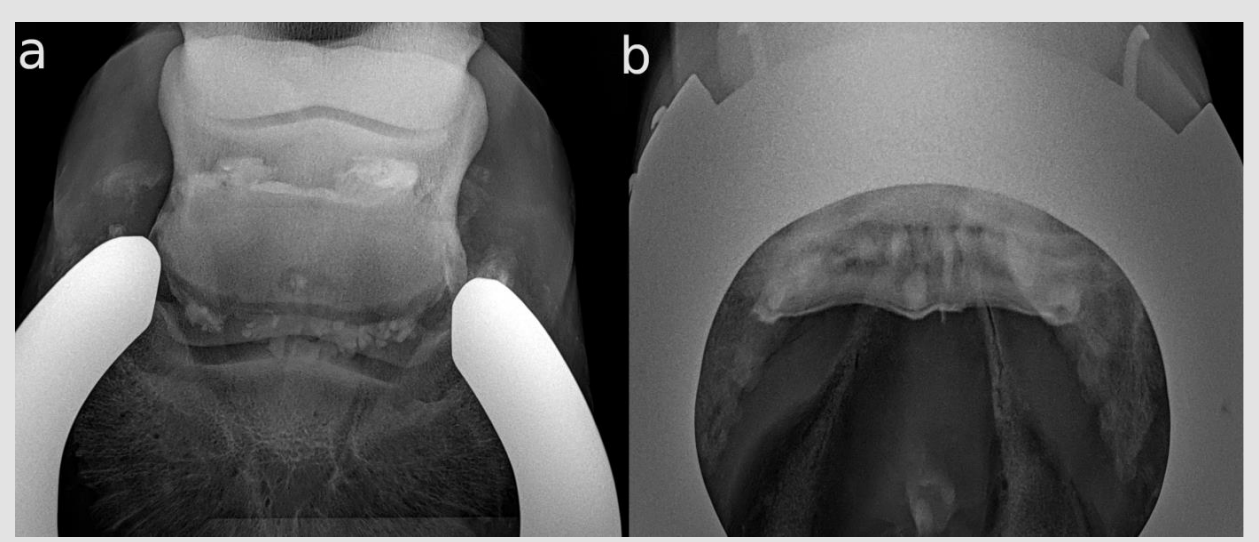

Figure 2: Contrast-enhanced (CE) X-rays of horse 3; lateral is to the left.

a. Dorsoproximal-palmarodistal oblique (DPr-PaDiO) CE view; in the middle of the suspected osseus cyst-like lesion (OCLL) is a round-shaped radiopaque shadow arising from an accumulation of $\mathrm{CM}$ at the level of the navicular bone. The proximal border of the NB is very irregular, which is suspected of being a massive adhesion between the collateral sesamoidean ligament (CSL) and the DDFT. There also seems to be an adhesion on the lateral sight of the distal border.

b. DPr-PaDiO CE: the suspected focal pool of CM is in the middle of the navicular bone and, thus, proof of the suspected OCLL. There is an irregularity in the border of the CM medial to the ridge of the navicular bone. This finding is indicative of a lesion in the DDFT.

Horse 11 has a chronic right front limb lameness (3/5). The distal digital nerve block was positive. The radiographs and ultrasound of the tendon in the heel region (not transcuneal) were without significant findings. The owners reported a history of stumbling. Because they did not want to make an MRI, the NB was injected and the additional CE views were obtained. There were several longitudinal (proximo-distal) straight and radiopaque lines in the DPr-PaDiO CE (Figure 3a). The horse was diagnosed with a DDFT tendonitis. Additionally, there was an irregular proximal border of the dye column. The horse was given a poor prognosis for riding but a guarded prognosis for a pasture retirement. A special shoe for DDFT tendonitis was advised. The horse was sound for two months and returned with recurrent lameness after three months. The suspected tendon tear had enlarged enormously (Figure 3b) and was not visible in the ultrasound of the pastern region. The prognosis given was now poor. A neurectomy was performed even with the assessment that the chance was very poor and the tendon tear would be progressive. Three months later the horse was euthanized because of lameness when walking. 


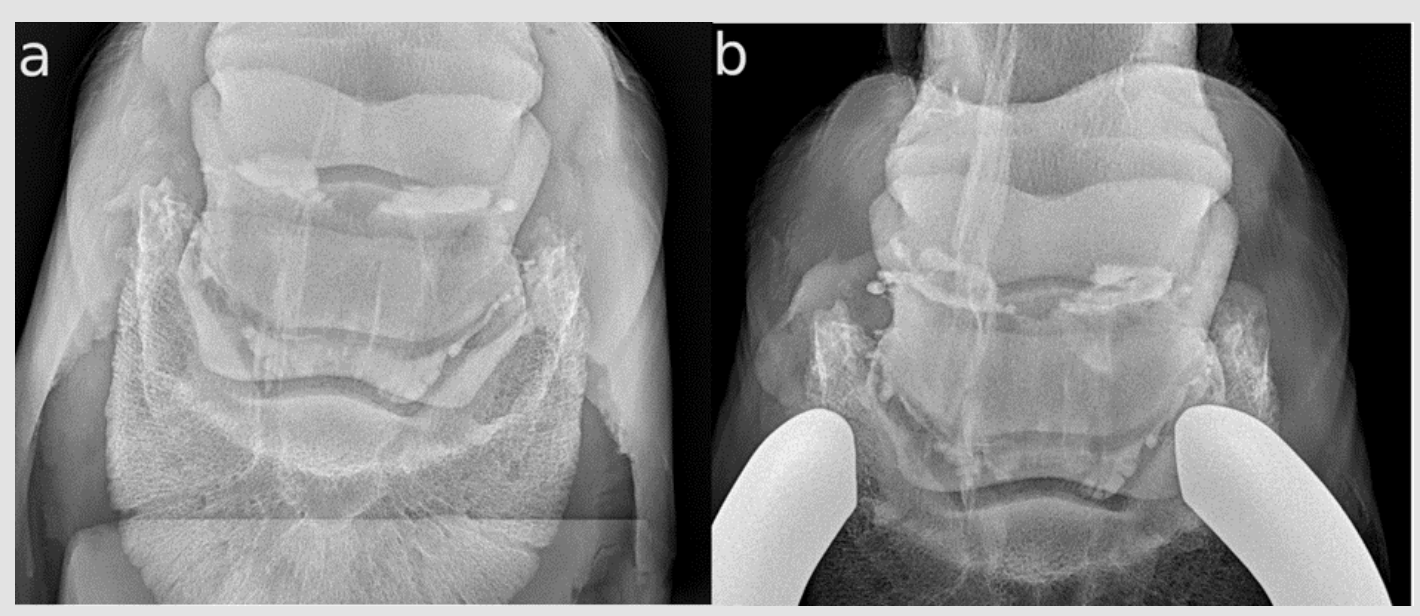

Figure 3: CE X-rays of horse 11, right front, lateral is to the left;

a. DPr-PaDiO CE view from May 28, 2019; there are several longitudinal (proximo-distal) straight radiopaque lines at the level of the NB. These lines were identified as dorsal DDFT lesions. The proximal border is very narrow to the proximal end of the navicular bone This seems to be a adhesion between the CSL and DDFT.

b. DPr-PaDiO CE view from August 21, 2019; the same findings as in a) but the lateral lesion of the DDFT has become much larger, reaching proximally an area where it could be easily seen in ultrasonography.

Horse 12 was lame $(1-2 / 5)$ in the right front limb. After the positive distal digital nerve block with a shift of lameness to the left side and no findings in ultrasound and X-ray, a bursography was performed. The bursography showed an accumulation of CM medial to the navicular bone in both views (Figures $4 \mathrm{a} \& 4 \mathrm{~b}$ ). In the DPr-PaDiO CE view, there was also a little bit of pooling of CM lateral to the ridge of the navicular bone. After the injection, the horse had acute lameness in a few steps (4/5). This lameness was gone after four hours and a single dose of flunixin-meglumin. The horse was diagnosed with a suspected traumatic rupture of the NB. The contralateral limb was also injected and showed no findings. It was given a good prognosis. After eight weeks rest and rehabilitation training, the horse was complete sound. There was a very clear end of the proximal dye column in the lateral and the DPr-PaDiO view (Figures 5a \& 5b) in 4/23 (17.39\%) legs compared to the other legs (Figures $5 \mathrm{c} \& 5 \mathrm{~d}$ ). In the lateral view, there was also a radiolucent area in the bursa, which seems to be air from the injection. Therefore, the air presents the proximal border of the NB. Three out of these four legs received $10 \mathrm{mg} / 1 \mathrm{ml}$ triamcinolonacetonide.

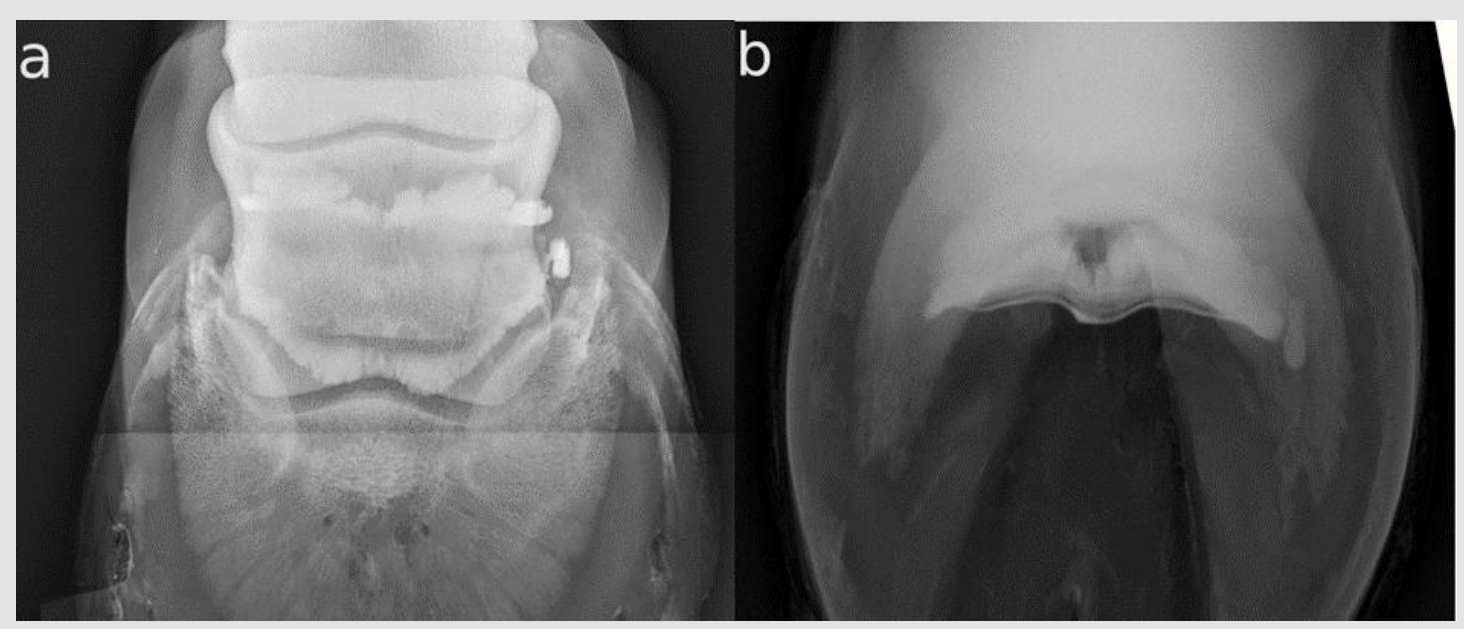

Figure 4: CE X-rays of horse 1,2 right front; lateral is to the left

a. The DPr-PaDiO X- ray shows that the proximal border of the NB has two outer pouches with normal invaginations, which represent the normal synovium of the NB. It is nearly the same in the distal border of the NB. Except for the pooling of CM on the medial site of the navicular bone, this seems to be a normal NB. The CM medial to the bursa has to be a small rupture of the NB;

b. The finding is reproducible in the DPr-PaDiO X-ray. In addition, a small pooling of CM lateral to the ridge of the navicular bone is visible 


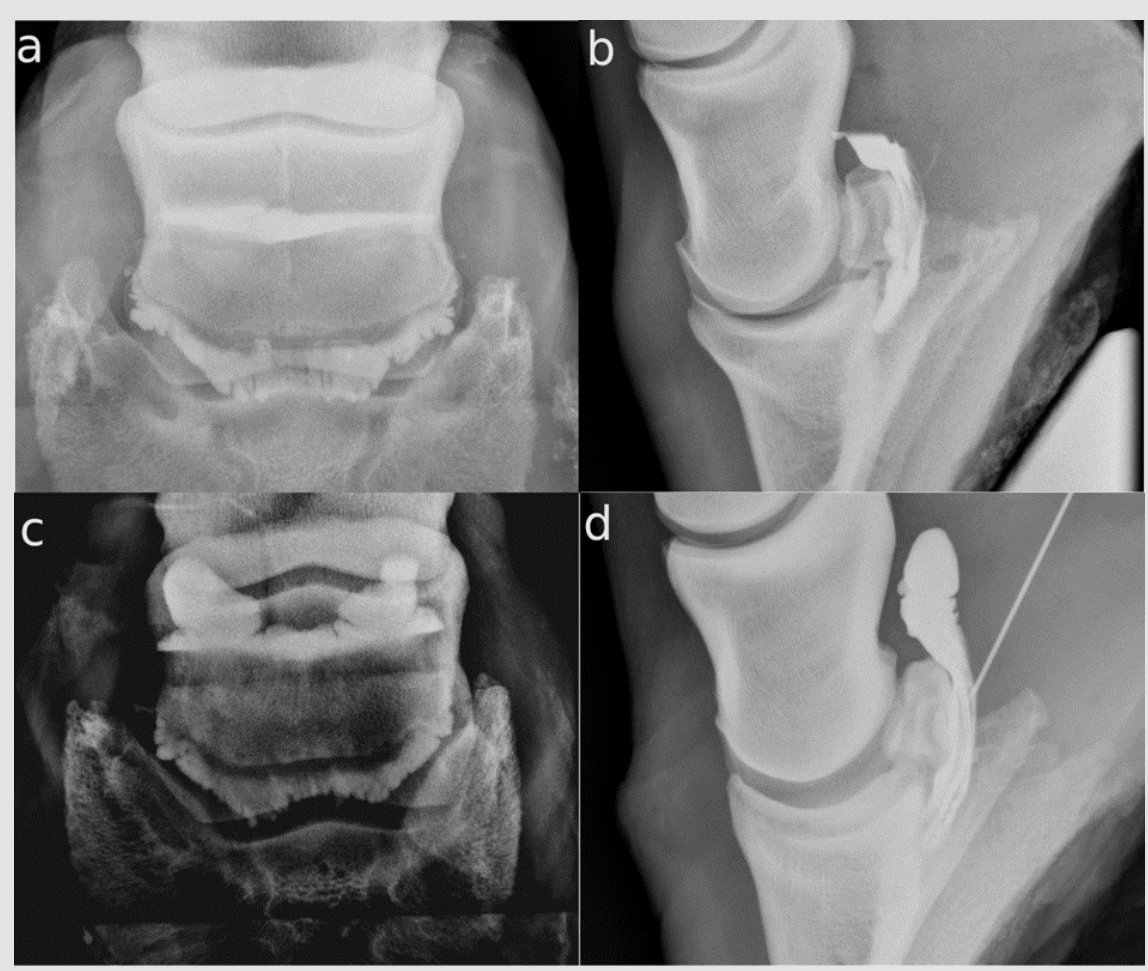

Figure 5:

A. a) DPr-PaDiO X-ray of horse 4; lateral is to the left. This shows a nearly horizontal and smooth proximal border of the CM;

B. b) lateral Image of the same horse as in a). The proximal border is also very sharp and nearly parallel to the ground. There is a radiolucent area in the estimated proximal border of the NB. The CM and the medication $(1 \mathrm{ml} / 10 \mathrm{mg}$ triamcinolone $)$ are arranged in two phases. This makes an evaluation of the proximal border of the NB impossible.

C. c) and d) The same projections of a cadaver limb injected with $3 \mathrm{ml} \mathrm{CM}$ without medication. The proximal border has two outer pouches and is round-shaped in the lateral view.

\section{Discussion}

The injection of the bursa is a crucial part of treating navicular disease [11]. There has been a lot of discussion about whether it is necessary to inject the bursa because medication of the DIP joint will diffuse to the NB anyway $[15,16]$. Therefore, whether to inject the bursa or not should be considered every time [17]. There can be a case of DDFT tendonitis after injecting the bursa [18]. If the decision to inject the bursa has been made, a contrast study [12] for a successful injection seems to be necessary. In our study, the success rate in living horses with an X-ray-guided injection was successful in 20/23 (86.96\%) cases, which is nearly the same as that reported previously: $14 / 17$ (82.35 \%) [14]. The reason for the difference between 23/25 (92\%) [19] and (96/96) $100 \%$ [13] seems to be the movement of a living horse. The horse is able to move in the time between making the lateral X-ray to check the needle placement and the injection. Even with the foot placed on the block, the lifted leg can fluctuate and the connected movement of the DDFT can move the needle.

The bursography revealed a diagnosis in $6 / 7$ cases. In two cases (horse 3 and 11), the prognosis based on the bursography was correct, even though one of these cases did not show marked alliterations in the radiographs. In these cases, a MRI was not necessary and saved the owner money and stress for the horse. The communication between the NB and the DIP joint, as in horse 1 , is also a finding which is perhaps not visible in the MRI. The same applies to the right front leg of horse 12 . The rupture of the NB may only be visible in the MRI with CM [20]. The mixture of the CM with another medication could be a problem in evaluating bursographies, as shown in Figure 5. The CM based on iodine had a higher density than other drugs. In addition, it does not seem to be dilutable in other drugs. Therefore, there can be two phases in the bursa: distal the CM and proximal the medication (e.g. triamcinolone), and perhaps air. But no problems seem to occur when mixing the CM with local anesthetics and injecting them into synovial structures [21,22]. One horse in this study developed an acute onset of lameness after the injection. No horse had a septic inflammation. The injection of up to $6 \mathrm{ml}$ in the bursa seems to be safe [20]. 
This is the first study on the DPr-PaDiO CE in living horses. No validated statistics could be made because of the low number of cases and the absence of a gold standard. The findings were compared with results from cadaver limbs [13]. Further research should be made to ensure these first results. This study shows that the injection of the NB should always be controlled with CM to be sure if the injection was successful. The bursography could lead to a diagnosis, a safer prognosis and a successful control for intrabursal treatment especially in cases where MRI or ultrasound examinations are not possible.

\section{Acknowledgement}

The authors gratefully acknowledge the managers of the abattoir for their valuable supportive efforts. Without their kind cooperation, this study would have been difficult to conduct.

\section{Authors' Contributions}

CS designed and carried out the study, performed statistical analyses, wrote the original draft, and edited and revised the manuscript. CS and JK evaluated the samples.

\section{Funding}

Not applicable.

\section{Availability of Data and Materials}

The datasets generated and/or analyzed during the current study are available from the corresponding author on reasonable request.

\section{Ethics Approval and Consent to Participate}

All horses were injected for clearly defined therapeutic reasons.

\section{Consent for publication}

Not applicable.

\section{Competing Interests}

The authors declare that they have no competing interests.

\section{References}

1. Rijkenhuizen ABM (2006) Navicular disease: a review of what's new. Equine Vet J 38: 82-88.

2. Dyson S, Murray R, Schramme M, Blunden T (2011) Current concepts of navicular disease. Equine Vet Educ 23: 27-39.

3. Gutierrez-Nibeyro SD, Werpy NM, Gold SJ, Olguin S, Schaeffer D] (2020) Standing MRI lesions of the distal interphalangeal joint and podotrochlear apparatus occur with a high frequency in warmblood horses. Vet Radiol Ultrasound 61: 336-345.

4. Kottmeier LK, Seehusen F, Helweg M, Rohn K, Stadler P, et al. (2020) High-field ( 3 Tesla) MRI of the navicular apparatus of sound horses shows good agreement to histopathology. Vet Radiol Ultrasound 61: 4857.

5. Murray RC, Mair TS, Sherlock CE, Blunden AS (2009) Comparison of high-field and low-field magnetic resonance images of cadaver limbs of horses. Vet Rec 165: 281-288.
6. Busoni V, Lahaye B, Denoix JM (2006) Transcuneal ultrasonographic findings in the podotrochlear apparatus: Comparison with postmortem in 14 equine digits. J Equine Vet Sci 26: 113-119.

7. Evrard L, Joostens Z, Vandersmissen M, Audigié F, Busoni V (2021) Comparison between ultrasonographic and standing magnetic resonance imaging findings in the podotrochlear apparatus of horses with foot pain. Front Vet Sci 8: 675180.

8. Dyson S (2008) Radiological interpretation of the navicular bone. Equine Vet Educ 20: 268-280.

9. Turner T (1998) Use of navicular bursography in 97 Horses. Proceedings of the $44^{\text {th }}$ Annual Convention of the AAEP, 1998, Baltimore, Maryland, USA.

10. Turner T (2013) How to perform and interpret navicular bursography. Proceedings of the $59^{\text {th }}$ Annual Convention of the American Association of Equine Practitioners, Nashville, Tennessee, USA, 7-11 December 2013, American Association of Equine Practitioners (AAEP), Lexington, pp. 197-202.

11. Marsh CA, Schneider RK, Sampson SN, Roberts GD (2012) Response to injection of the navicular bursa with corticosteroid and hyaluronan following high-field magnetic resonance imaging in horses with signs of navicular syndrome: 101 cases (2000-2008). J Am Vet Med Assoc 241: 1353-1364.

12. Verschooten F, Desmet P, Peremans K, Picavet T (1990) Navicular disease in the horse: the effect of controlled intrabursal corticoid injection. J Equine Vet Sci 10: 316-320.

13. Staufenbiel C, Gergards H, Koerner J (2021) Blinded comparison of contrast radiography of navicular bursa in dissected horse front feet with radiographs and gross pathology. "in Press" Vet Research Communications.

14. Piccot-Crézollet C, Cauvin ER, Lepage OM (2005) Comparison of two techniques for injection of the podotrochlear bursa in horses. J Am Vet Med Assoc 226: 1524-1528.

15. Boyce M, Malone ED, Anderson LB, Park S, Godden SM, et al. (2010) Evaluation of diffusion of triamcinolone acetonide from the distal interphalangeal joint into the navicular bursa in horses. Am J Vet Res 71: $169-175$.

16. Manfredi JM, Boyce M, Malone ED, Anderson C, Anderson LB, etal. (2012) Steroid diffusion into the navicular bursa occurs in horses affected by palmar foot pain. Vet Rec 171: 642 .

17. Labens R, Redding WR (2012) The dilemma of whether to inject the navicular bursa. Vet Rec 171: 641-642.

18. Froydenlund TJ, Meehan LJ, Morrison LR, Labens R (2017) A rare case of deep digital flexor tendinopathy following centesis of the navicular bursa. Front Vet Sci 4: 169.

19. Schramme M, Boswell J, Hamhougias K, Toulson K, Viitanen M (2000) An in vitro study to compare 5 different techniques for injection of the navicular bursa in the horse. Equine Vet I 32: 263-7.

20. Maher MC, Werpy NM, Goodrich LR, Mcllwraith CW (2011) Positive contrast magnetic resonance bursography for assessment of the navicular bursa and surrounding soft tissues. Vet Radiol Ultrasound 52: 385-393.

21. Agass R, Dixon J Fraser B (2018) Computed tomographic contrast tenography of the digital flexor tendon sheath of the equine hindlimb. Vet Radiol Ultrasound 59: 279-288.

22. Kent AV, Chesworth MJ, Wells G, Gerdes C, Bladon BM, et al. (2020) Improved diagnostic criteria for digital flexor tendon sheath pathology using contrast tenography. Equine Vet J 52: 205-212. 
ISSN: 2574-1241

DOI: 10.26717/BJSTR.2021.40.006476

Christian Staufenbiel. Biomed J Sci \& Tech Res

(C) (P) This work is licensed under Creative

Submission Link: https://biomedres.us/submit-manuscript.php

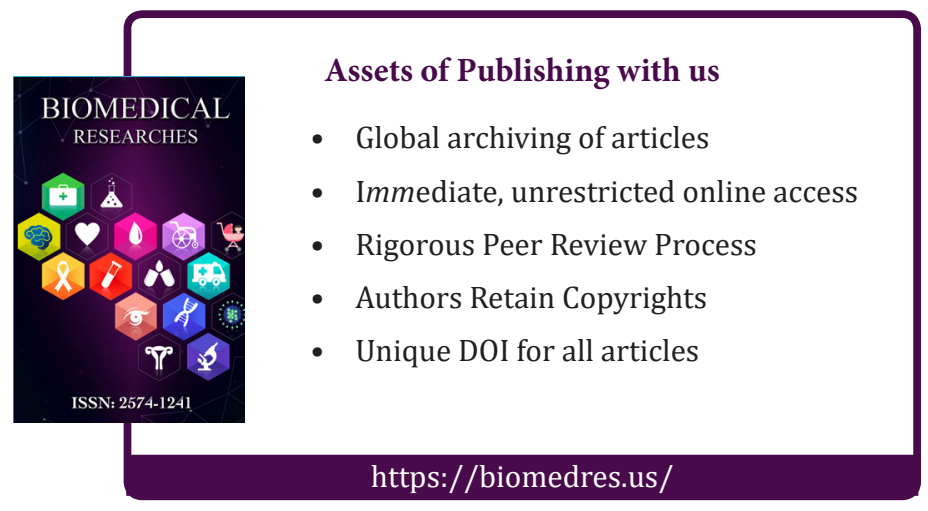

